\section{Reimbursement Policies for Diabetes Prevention Program (DPP): Implications for Racial and Ethnic Health Disparities}

Taynara Formagini, M.Sc. ${ }^{1}$, Joanna V. Brooks, MBE, Ph.D. .,2, Lisette T. Jacobson, MPA, Ph.D. ${ }^{3}$, Andrew W. Roberts, Pharm.D., Ph.D., ${ }^{1,24}$

${ }^{1}$ University of Kansas School of Medicine, Kansas City, KS Department of Population Health

${ }^{2}$ University of Kansas Cancer Center, Kansas City, KS ${ }^{3}$ University of Kansas School of Medicine-Wichita, Wichita, KS

Department of Population Health

${ }^{4}$ University of Kansas School of Medicine, Kansas City, KS Department of Anesthesiology

Received Jan. 26, 2021; Accepted for publication April 30, 2021; Published online Sept. 1, 2021 https: /oi.org 10.17161/lim.vol1415125

\section{INTRODUCTION}

Black and Latinx individuals face many diabetes-related disparities compared to non-Hispanic Whites..$^{1-3}$ In 2002, The Diabetes Prevention Program (DPP) clinical trial demonstrated a 58\% reduction in diabetes incidence among adults with prediabetes who reduced their body weight by 5 - 7\%. ${ }^{4}$ In 2018, Medicare started offering reimbursement to healthcare and community organizations delivering the DPP, using a performance-based payment methodology that does not account for racial and ethnic disparities. ${ }^{5}$ Blacks and Latinxs are less likely than non-Hispanic Whites to achieve the performance benchmark required for full DPP reimbursement, ${ }^{6}$ which can discourage providers from delivering DPP to these groups. ${ }^{7}$ We discuss how the Medicare DPP reimbursement model and the dismissal of racial and ethnic disparities associated with diabetes are problematic and provide alternative approaches to adapt Medicare reimbursement for DPP to mitigate disparities in diabetes prevention efforts.

\section{Diabetes Prevention and the Medicare Reimbursement Program}

Blacks and Latinxs face striking injustices and disparities in health outcomes and healthcare services in the United States. ${ }^{1}$ Type 2 diabetes (hereafter referred to as diabetes) is one disease where these disparities are clear. ${ }^{3}$ Compared to non-Hispanic Whites, Blacks and Latinxs face higher rates of diabetes prevalence, worse diabetes control, and higher rates of diabetes-related complications and mortality. ${ }^{2}$ These diabetes-related health disparities are projected to worsen through $2030 .{ }^{8}$ Therefore, delivering effective preventive interventions for Black and Latinx individuals with prediabetes can reduce diabetes-related disparities for these groups while also reducing the burden of diabetes nationwide, and reducing the high costs associated with the disease. ${ }^{1}$

To date, the best evidence for guiding strategies to prevent diabetes at the individual level comes from randomized clinical trials of lifestyle interventions (i.e., adherence to a healthy diet and physical activity), such as the Diabetes Prevention Program (DPP). ${ }^{4}$ The DPP clinical trial published in 2002 demonstrated that a mean body weight loss of 5 - 7\% among adults with impaired glucose tolerance or impaired fasting glucose (known as prediabetes) led to a $58 \%$ reduction in diabetes incidence after three years. ${ }^{4}$ Blacks and Latinxs represented $35.6 \%$ of the sample and the incidence of diabetes was similar among non-Hispanic Whites, Blacks, and Latinxs, which gives support to the

\section{KANSAS JOURNAL of MEDICINE}

claim that the DPP is effective for these two minority groups under experimental conditions. The original findings, followed by a 10-year follow-up study that reaffirmed positive benefits on diabetes incidence outcomes, ${ }^{9}$ led to implementation of the National Diabetes Prevention Program (National DPP) in 2012.

The National DPP is a year-long lifestyle change program administered through healthcare and community organizations that partner with the U.S. Centers for Disease Control and Prevention (CDC). Key features of the program include a 16-session core curriculum focused on a healthy diet and physical activity, and regular engagement with a certified lifestyle coach and group support sessions over the course of a year. The primary measure of the DPP's effectiveness is participants' percentage change in body weight from the beginning to end of the intervention. ${ }^{6}$

A report from the National DPP released by the CDC showed that between 2012 and 2016, 14,747 adults with prediabetes participated in the program in healthcare and community settings, of which $13.8 \%$ were Blacks and $10 \%$ were Latinxs. ${ }^{6}$ Following the findings of the original clinical trial, ${ }^{49}$ a minimum of a $5 \%$ reduction of body weight was set as a benchmark for success for all participants in the program. However, only $35.5 \%$ of all participants, compared with $70 \%$ in the clinical trial, achieved the goal of at least a $5 \%$ body weight reduction. ${ }^{6}$ Compared to non-Hispanic Whites, Blacks and Latinxs who participated in the National DPP were half as likely to achieve a $5 \%$ weight loss. Similarly, multiple implementation studies have shown that compared to nonHispanic Whites, Blacks and Latinxs are less likely to enroll in the DPP and to lose body weight. ${ }^{10-14}$ In general, studies have discussed lower engagement to the intervention (i.e., adherence to a healthy diet and physical activity) and other non-intervention related factors, such as social, economic, and environmental factors, as the main reasons for low enrollment and low effectiveness among these groups. ${ }^{10-14}$

In 2018, Medicare started offering reimbursement to healthcare and community organizations delivering the DPP to incentivize broader adoption of this intervention among the 24 million seniors with prediabetes in the U.S. (the equivalent of $46 \%$ of the U.S. population with 65 years or older). ${ }^{15}$ Of note, Black and Latinx Medicare beneficiaries have a higher prevalence of diabetes compared to non-Hispanic Whites (38\%,38\%, versus 23\%, respectively). Implementing Medicare reimbursement for the DPP provides an important policy conduit for potentially addressing these high rates of diabetes prevalence among both Blacks and Latinxs.

Medicare reimbursement for DPP services is contingent on a performance-based payment methodology. Full Medicare reimbursement for delivering the DPP requires that participants achieve the $5 \%$ weight loss benchmark established by the earlier clinical trial. ${ }^{4}, 9$ DPP reimbursement is reduced significantly starting with month six of the program if individual participants have not achieved the required weight loss. For example, from months 7 - 12, providers can receive up to $\$ 124$ per participant if the required weight loss is achieved, but only 
KANSAS JOURNAL of MEDICINE

REIMBURSEMENT FOR DPP

continued.

$\$ 30$ per participant who does not achieve the required weight loss (Table 1). Payment is not risk-adjusted for economic, social, and environmental factors and does not account for findings from the National $\mathrm{DPP}^{6}$ and from other studies ${ }^{10-14}$ that show Black and Latinx participants are less likely to achieve the $5 \%$ weight loss benchmark.

\section{Limitations of Medicare DPP Reimbursement: Disadvantages for Blacks and Latinxs}

When Medicare reimbursement for the DPP was first announced, it received immediate criticism based on concerns that the structure of the reimbursement would discourage broad dissemination of the program and widen health disparities. Ritchie et al. ${ }^{16}$ offered an analysis on critical limitations of this reimbursement model, calling attention to the fact that tying payment to a $5 \%$ weight loss outcome was likely to discourage providers serving minority populations to offer the program, since these populations are less likely to achieve the $5 \%$ benchmark due to economic, social, and environmental factors. Later, at least two analyses projected that Medicare reimbursement might be insufficient to cover the DPP's costs, particularly for healthcare systems serving a majority of Black and Latinx participants. ${ }^{7.17}$ Unsurprisingly, a recent analysis shows 9 of the 10 states with the largest population of Blacks and Latinxs have severe shortages of Medicare DPP providers. ${ }^{18}$

Greater DPP uptake among non-Hispanic Whites and less access among Blacks and Latinxs have the potential to exacerbate the previously discussed diabetes-related health disparities by increasing the gap in the prevalence of diabetes between these two minority groups and non-Hispanic Whites. Yet, no changes have been made to the Medicare DPP reimbursement model to date to address the fact that Blacks and Latinxs experience systemic barriers to achieving the 5\% weight loss benchmark required by the Medicare DPP reimbursement model, and simultaneously have higher rates of diabetes. Moreover, other large payers, including Medicaid, have started to follow the same model to reimburse for the DPP. 5,19

\section{Dismissal of Racial and Ethnic Disparities in DPP Reimburse- ment}

By not adjusting payment for economic, social, and environmental factors influencing weight loss success, Medicare reimbursement for the DPP maintains the predominant biomedical model approach used in the U.S. healthcare system. This approach views diabetes prevention solely as an individual effort and responsibility, feasible through adherence to a healthy diet and physical activity. This model of reimbursement disregards that Black and Latinx populations are less likely to achieve the required weight loss due to structural and systemic barriers outside of individual behaviors. In other words, this approach fails to account for economic, social, and environmental factors that influence behavior change and are particularly important to individuals attempting to prevent diabetes.

First, Blacks and Latinxs face challenges related to economic factors. Blacks and Latinxs have the lowest household income in the U.S. ${ }^{20}$ Among Medicare beneficiaries, a total of 19\% of Blacks and 18\% of
Latinxs are below $100 \%$ of the Federal Poverty Level compared to $8 \%$ of non-Hispanic Whites. ${ }^{15}$ Limited economic resources generally are linked to higher consumption of a poor diet quality and less engagement in recreational physical activity, which in turn, are associated with obesity. ${ }^{21,22}$

Social and environmental factors, such as where a person lives and works, have an important impact on diet quality and physical activity as well. Neighborhoods with a large concentration of Blacks and Latinxs tend to have less access to healthy food options; Blacks and Latinxs also experience fewer opportunities to exercise and lower quality resources. ${ }^{23,24}$ Additionally, they are more likely to have low-paying.jobs with worse working conditions, more work hours, and fewer benefits. ${ }^{25}$ Taken together, these factors may be associated with less available time to exercise and to buy and cook healthy foods. Moreover, Blacks and Latinxs are less likely to try to lose weight. ${ }^{26}$ Among middle-aged and older adults (the majority of DPP participants), Blacks and Latinxs are significantly less likely than non-Hispanic Whites to engage in physical activity and healthy dietary behaviors for weight loss. ${ }^{27}$

These realities help to explain why Blacks and Latinxs have been less likely to achieve the expected $5 \%$ body weight reduction compared to non-Hispanic Whites. However, the current $5 \%$ weight loss benchmark for Medicare DPP reimbursement ignores these systemic economic, social, and environmental barriers that disadvantage these two minority groups. Assuring that reimbursement for the DPP is equitable for different populations is imperative, as it can help to mitigate racial and ethnic disparities in the burden of diabetes for millions of individuals in the country.

\section{Accounting for Racial and Ethnic Disparities in the DPP Reim- bursement Model}

Medicare and other payers should consider alternative reimbursement approaches for the DPP. Particularly, to improve DPP outcomes for Blacks and Latinxs and reduce the harmful consequences of racial and ethnic disparities in disease burden of diabetes, payers and health systems considering reimbursement models could improve upon the current Medicare DPP model to address disparities in at least three different ways.

First, as others have recommended,${ }^{16}$ we suggest revising the $5 \%$ weight loss threshold for full reimbursement. While the $5 \%$ weight reduction should be encouraged, previous studies have shown a linear association between any body weight reduction and reduction of diabetes incidence, ${ }^{28,29}$ suggesting that any reduction of body weight can be beneficial in attempting to prevent diabetes. Therefore, we recommend that sites receive full reimbursement if participants reduce and maintain some body weight. Revising this threshold has the potential to encourage providers to deliver the DPP intervention to more participants from racial and ethnic populations and increase the likelihood of Blacks and Latinxs to receive the intervention.

Second, reimbursement should be risk-adjusted based on beneficiaries' socioeconomic status and race/ethnicity, an approach that has been used previously by other Medicare efforts. ${ }^{30,31}$ These are two measurable social risk factors that should be considered in DPP reimbursement. Sites providing care to low-income Blacks and Latinxs should receive an adjusted rate for each participant. These participants may require more intensive care and greater costs to overcome 
Table 1. Medicare DPP payment structure.

\begin{tabular}{|c|c|c|c|c|c|c|c|}
\hline & $\begin{array}{l}\text { Core Sessions } \\
\text { Months 0 - } 6\end{array}$ & \multicolumn{2}{|c|}{$\begin{array}{c}\text { Core maintenance sessions } \\
\text { Months } 7 \text { - } 12\end{array}$} & \multicolumn{4}{|c|}{$\begin{array}{l}\text { Ongoing maintenance sessions } \\
\text { Months } 13-24\end{array}$} \\
\hline & 16 sessions & 3 sessions & 3 sessions & 3 sessions & 3 sessions & 3 sessions & 3 sessions \\
\hline $\begin{array}{l}\text { Attendance } \\
\text { only }\end{array}$ & $\begin{array}{l}\text { Attend } 1 \text { session } \\
\text { total: } \$ 26 \text { (G9873) } \\
\text { Attend } 4 \text { sessions } \\
\text { total: } \$ 52 \text { (G9874) } \\
\text { Attend } 9 \text { sessions } \\
\text { total: } \$ 94 \text { (G9875) } \\
\end{array}$ & $\begin{array}{c}\text { Attend } 2 \text { sessions } \\
\text { (without at least } \\
5 \% \text { WL): } \$ 15 \\
\text { (G9876) }\end{array}$ & $\begin{array}{c}\text { Attend } 2 \text { sessions } \\
\text { (without at least } \\
5 \% \text { WL): } \$ 15 \\
\text { (G9877) }\end{array}$ & \multicolumn{4}{|c|}{$\begin{array}{l}5 \% \mathrm{WL} \text { and attendance must be achieved to receive payment during ongoing } \\
\text { maintenance sessions }\end{array}$} \\
\hline $\begin{array}{l}\text { Attendance } \\
\text { and weight } \\
\text { loss }\end{array}$ & $\begin{array}{c}5 \% W L \text { is not } \\
\text { required to receive } \\
\text { payment }\end{array}$ & $\begin{array}{c}\text { Attend } 2 \text { sessions } \\
\text { (with at least } \\
5 \% \text { WL): \$63 } \\
\text { (G9878) }\end{array}$ & $\begin{array}{c}\text { Attend } 2 \text { sessions } \\
\text { (with at least } \\
5 \% \text { WL): } \$ 63 \\
\text { (G9879) }\end{array}$ & $\begin{array}{c}\text { Attend } 2 \text { sessions } \\
\text { (with at least } \\
5 \% \text { WL): } \$ 52 \\
\text { (G9882) }\end{array}$ & $\begin{array}{c}\text { Attend } 2 \text { sessions } \\
\text { (with at least } 5 \% \\
\text { WL): } \$ 52 \\
\text { (G9883) }\end{array}$ & $\begin{array}{c}\text { Attend } 2 \text { sessions } \\
\text { (with at least } \\
5 \% \text { WL): } \$ 52 \\
\text { (G9884) }\end{array}$ & $\begin{array}{l}\text { Attend } 2 \text { sessions } \\
\text { (with at least } \\
5 \% \text { WL): } \$ 52 \\
\text { (G9885) }\end{array}$ \\
\hline \multirow{4}{*}{$\begin{array}{l}\text { Additional } \\
\text { codes }\end{array}$} & \multicolumn{3}{|c|}{ 5\% WL achieved: \$165 (G9880) } & & & & \\
\hline & \multicolumn{7}{|c|}{ 9\% WL achieved: $\$ 26$ (G9881) } \\
\hline & \multicolumn{7}{|c|}{ Bridge payment: $\$ 26$ (G9890) } \\
\hline & \multicolumn{7}{|c|}{$\begin{array}{l}\text { Report attendance at sessions that are not associated with a performance goal. Non-payable codes should be listed on the same claim as the } \\
\text { payable code with which they are associated: } \$ 0 \text { (G9891) }\end{array}$} \\
\hline
\end{tabular}

Maximum possible payment per eligible beneficiary: $\$ 689$;

Table adapted from Medicare Diabetes Prevention Program (MDPP) Quick Reference Guide to Payment and Billing.

barriers they face to achieving the same outcomes as more advantaged participants. ${ }^{31}$ Doing so may prevent underpayment and appropriately incentivize sites serving Blacks and Latinxs to provide the program for these groups.

Third, payers could consider providing supplemental financial support to low-income participants to offset the costs of healthy meals and access to physical activity-related facilities aiming to overcome some of the barriers faced by these individuals to engaging in behavior change. These two strategies were used on the original DPP clinical trial $^{4}$ and as others have shown, it can increase participants' likelihood of eating healthier food and exercising, and improve DPP attendance, ${ }^{32,33}$ which in turn may improve weight loss outcomes.

\section{CONCLUSIONS}

In short, the DPP has been shown to prevent diabetes effectively among Blacks and Latinxs under ideal experimental conditions. ${ }^{4}$ However, Medicare's current reimbursement model for the DPP overlooks the fact that Blacks and Latinxs are less likely to achieve the required weight loss under real world conditions. Medicare also is dismissing the data showing reimbursement is insufficient to cover the program's cost for these populations. This model appears to be insufficient for creating widespread adoption of the DPP among sites caring for Black and Latinx beneficiaries by discouraging providers serving these groups to pursue the DPP. Even though reimbursement for the DPP, as one policy, is unable to address all economic, social, and environmental factors or to eliminate health disparities fully, the current reimbursement model is poised to exacerbate disparities by further disadvantaging the quantity and quality of DPP services delivered to Blacks and Latinxs. A new risk adjusted DPP reimbursement model may pave the way to improved prevention of diabetes and mitigation of racial and ethnic disparities in the disease burden of diabetes. While we intended to provide initial evidence about the need to consider alternative approaches for reimbursement of the DPP, more robust evidence is needed to determine best practices and optimal reimbursement benefit designs for improving DPP uptake among racial and ethnic minority populations and improving diabetes prevention outcomes. Interventions addressing providers knowledge about delivering the DPP for Blacks and Latinxs also can be useful to improve access to the DPP for these groups.

\section{ACKNOWLEDGMENTS}

Taynara Formagini was supported by a scholarship from the Brazilian Coordination for the Improvement of Higher Education Personnel (CAPES) to pursue doctoral education. Dr. Andrew Roberts was supported by a career development grant from the National Center for Advancing Translational Science awarded to the Frontiers: University of Kansas Clinical and Translational Science Institute (\#KL2TR002367).

\section{REFERENCES}

${ }^{1}$ Smedley BD, Stith AY, Nelson AR. Institute of Medicine, Committee on Understanding and Eliminating Racial and Ethnic Disparities in Health Care. Unequal treatment: Confronting racial and ethnic disparities in healthcare. Washington, DC: National Academies Press, 2003.

2 Spanakis EK, Golden SH. Race/ethnic difference in diabetes and diabetic complications. Curr Diab Rep 2013; 13(6):814-823. PMID: 24037313.

${ }^{3}$ Hill-Briggs F, Adler NE, Berkowitz SA, et al. Social determinants of health and diabetes: A scientific review. Diabetes Care 2020; 44(1):258-279. PMID: 33139407.

${ }^{4}$ Diabetes Prevention Program Research Group, et al. 10-year follow-up of diabetes incidence and weight loss in the Diabetes Prevention Program Outcomes Study. Lancet 2009; 374(9702):1677-1686. PMID: 19878986.

${ }^{5}$ National DPP Coverage Toolkit. National Diabetes Prevention Program Coverage Toolkit: Participating Payers and Employers. 2020. https://coveragetoolkit.org/participating-payers/. Accessed October 9, 2020.

${ }^{6}$ Ely EK, Gruss SM, Luman ET, et al. A national effort to prevent type 2 diabetes: participant-level evaluation of CDC's National Diabetes Prevention Program. Diabetes Care 2017; 40(10):1331-1341. PMID: 28500215. 


\section{KANSAS JOURNAL of MEDICINE}

REIMBURSEMENT FOR DPP continued.

7 Ritchie ND, Gritz RM. New Medicare diabetes prevention coverage may limit beneficiary access and widen health disparities. Med Care 2018; 56(11):908-911. PMID: 30312286.

${ }^{8}$ Rowley WR, Bezold C, Arikan Y, Byrne E, Krohe S. Diabetes 2030: Insights from yesterday, today, and future trends. Popul Health Manag 2017; 20(1):6-12. PMID: 27124621.

9 Diabetes Prevention Program Research Group, et al. 10-year follow-up of diabetes incidence and weight loss in the Diabetes Prevention Program Outcomes Study. Lancet 2009; 374(9702):1677-1686. PMID: 19878986.

10 Wadden TA, West DS, Neiberg RH, et al. One-year weight losses in the Look AHEAD study: Factors associated with success. Obesity (Silver Springs) 2009; 17(4):713-722. PMID: 19180071.

11 Wing RR, Hamman RF, Bray GA, et al. Achieving weight and activity goals among diabetes prevention program lifestyle participants. Obes Res 2004; 12(9):1426-1434. PMID: 15483207.

12 West DS, Prewitt TE, Bursac Z, Felix HC. Weight loss of black, white, and Hispanic men and women in the Diabetes Prevention Program. Obesity (Silver Spring) 2008; 16(6):1413-1420. PMID: 18421273.

${ }^{13}$ AuYoung M, Moin T, Richardson CR, Damschroder LJ. The Diabetes Prevention Program for underserved populations: A brief review of strategies in the real world. Diabetes Spectr 2019; 32(4):312-317. PMID: 31798288.

${ }^{14}$ Samuel-Hodge C, Johnson C, Braxton D, Lackey M. Effectiveness of Diabetes Prevention Program translations among African Americans. Obes Rev 2014; 15(Suppl 4):107-124. PMID: 25196409.

${ }^{15}$ Kaiser Family Foundation (KFF). Profile of Medicare Beneficiaries by Race and Ethnicity: A Chartpack. Washington, DC: Kaiser Family Foundation (KFF), 2016.

16 Ritchie ND, Havranek EP, Moore SL, Pereira RI. Proposed Medicare coverage for diabetes prevention: Strengths, limitations, and recommendations for improvement. Am J Prev Med 2017; 53(2):260-263. PMID: 28336351.

${ }_{17}$ Parsons AS, Raman V, Starr B, Zezza M, Rehm CD. Medicare underpayment for Diabetes Prevention Program: Implications for DPP suppliers. Am J Manag Care 2018; 24(10):475-478. PMID: 30325189.

18 Ritchie ND, Sauder KA, Gritz RM. Medicare Diabetes Prevention Program: Where are the suppliers? Am J Man Care 2020; 26(6):el98-e201. PMID: 32549070.

19 Porterfield D, Jacobs S, Farrell K, et al. Evaluation of the Medicaid Coverage for the National Diabetes Prevention Program Demonstration Project. Final Report Research. Triangle Park, NC RTI International Research Institute, 2018 .

${ }^{20}$ Wilson V, Williams J. Racial and ethnic income gaps persist amid uneven growth in household incomes. September 11, 2019. https://www.epi.org/ blog/racial-and-ethnic-income-gaps-persist-amid-uneven-growth-inhousehold-incomes/.Accessed Nov 11, 2019.

${ }^{21}$ Darmon N, Drewnowski A. Does social class predict diet quality? Am J Clinical Nutr 2008; 87(5):1107-1117. PMID: 18469226.

${ }^{22}$ Stalsberg R, Pedersen AV. Are differences in physical activity across socioeconomic groups associated with choice of physical activity variables to report? Int J Environ Res Public Health 2018; 15(5):922. PMID: 29734745. ${ }^{23}$ Walker RE, Keane CR, Burke JG. Disparities and access to healthy food in the United States: A review of food deserts literature. Health Place 2010; 16(5):876-884. PMID: 20462784.

${ }^{24}$ Heinrich KM, Lee RE, Suminski RR, et al. Associations between the built environment and physical activity in public housing residents. Int J Behav Nutr Phys Act 2007; 4(1):56. PMID: 17997820.

${ }^{25}$ Carnevale A, Strohl J, Gulish A, Van Der Werf M, Peltier Campbell K. The Unequal Race for Good Jobs: How Whites Made Outsized Gains in Education and Good Jobs Compared to Blacks and Latinos. 2019. https://lgyhoq479ufd3yna29x7ubjn-wpengine.netdna-ssl.com/wpcontent/uploads/Full_Report-The_Unequal_Race_for_Good_Jobs.pdf. Accessed February 3, 2021.

${ }^{26}$ Marquez B, Murillo R. Racial/ethnic differences in weight-loss strategies among US adults: National Health and Nutrition Examination Survey 20072012. J Acad Nutr Diet 2017; 117(6):923-928. PMID: 28330732.

${ }_{27}$ August KJ, Sorkin DH. Racial/ethnic disparities in exercise and dietary behaviors of middle-aged and older adults. J Gen Intern Med 2011; 26(3):245-250. PMID: 20865342.

${ }^{28}$ Kim ES, Jeong JS, Han K, et al. Impact of weight changes on the incidence of diabetes mellitus: A Korean nationwide cohort study. Sci Rep 2018; 8(1):3735. PMID: 29487293.
${ }^{29}$ Hamman RF, Wing RR, Edelstein SL, et al. Effect of weight loss with lifestyle intervention on risk of diabetes. Diabetes Care 2006;29(9):2102-2107. PMID: 16936160.

${ }^{30}$ Durfey SNM, Kind AJH, Gutman R, et al. Impact of risk adjustment for socioeconomic status on Medicare Advantage plan quality rankings. Health Aff (Millwood) 2018; 37(7):1065-1072. PMID: 29985685.

${ }^{31}$ Steinwachs DM, Stratton KR, Kwan LY. Accounting for Social Risk Factors in Medicare payment. Washington, DC: National Academies Press, 2016. ISBN: 0-309-44801-8.

${ }^{32}$ Alva ML, Romaire M, Acquah J. Impact of financial incentives on diabetes prevention class attendance and program completion: Evidence from Minnesota, Montana, and New York. Am J Health Promot 2019;33(4):601-605. PMID: 30122055.

33 Desai JR, O'Connor PJ, Taylor GL, et al. 688-P: Factors associated with Diabetes Prevention Program (DPP) compliance and weight loss among low income participants. Diabetes 2019; 68(Suppl 1):688-P.

Keywords: minority health, Medicare, health insurance reimbursement, healthcare disparities, prediabetic state 